\title{
A Jurisdição Administrativa na Alemanha: entre Tarefas Clássicas e Desafios Atuais
}

\author{
EBERHARD SCHMIDT-AßMANN \\ Professor Emérito de Direito Público na Universidade de Heidelberg.
}

Submissão: 18.12 .2014

Decisão editorial: 29.04.2015

Comunicação ao autor: 29.04.2015

Tradução: Geraldo de Carvalho

SUMÁRIO: I - Introdução: Tribunais administrativos em uma "cultura administrativa legalista"; II - As principais características da jurisdição administrativa alemã (panorama); Modelo dualista; Tribunais administrativos como um dos pilares de apoio do Terceiro Poder; Somente tarefas da jurisprudência; Entrelaçamento de tribunais dos Estados e da União ("sistema misto"); III - Experiências com a constitucionalização do direito processual administrativo: o papel das garantias de tutela jurisdicional, especificamente, do artigo 19, alínea 4, da Lei Fundamental de 1949; III.1 "0 direito administrativo como direito constitucional concretizado": uma fórmula antiga para a constitucionalização do direito administrativo; III.2 Especial sobre o preceito constitucional da efetividade da tutela jurisdicional no direito processual e na prática dos tribunais administrativos; IV - A exatidão das revisões judiciais: "controle de intensidade" como tema clássico e atual; IV.1 0 princípio do controle total baseado na norma do Direito; IV.2 Exceções conforme "autorização normativa"; IV.3 Critérios para um controle judicial reduzido; V - 0 desafio dos "conflitos baseados em informação"; V.1 0 que são conflitos baseados em informação?; Proteção de dados, freedom of information, política de informação administrativa ativa (p. ex., informações ao consumidor), acesso a informações sigilosas por meio de equipamentos técnicos (p. ex., monitoramento eletrônico da esfera privada); V.2 0 problema de uma tutela jurisdicional imediata; a) "A Administração Pública não deve simplesmente partir para 0 ato"; b) Levantamento secreto de informação: "reserva de jurisdição"; V.3 0 tratamento de informações sigilosas no processo administrativo: processo a portas fechadas; $\mathrm{VI}$ - Conclusão: A relação complementar entre a jurisdição administrativa e as ciências jurídicas administrativas: dogmática do direito administrativo.

\section{TEXTO DA PALESTRA}

\section{I- INTRODUÇÃO: TRIBUNAIS ADMINISTRATIVOS EM UMA “CULTURA ADMINISTRATIVA LEGALISTA”}

Se compararmos as culturas administrativas, podemos dizer que a Alemanha é um representante da "cultura administrativa legalista"1. Culturas administrativas desse tipo têm três aspectos característicos:

1 König (Org.), Grundmuster der Verwaltungskultur, 2014. 
- $\quad$ elas têm um pessoal administrativo de formação essencialmente jurídica;

- $\quad$ elas partem da força de controle da lei parlamentar em relação à Administração Pública (o que pressupõe uma precisão suficiente das leis);

- elas confiam na capacidade dos tribunais para a solução dos conflitos entre cidadãos e Administrações Públicas de acordo com os critérios legais.

Os tribunais administrativos têm uma posição central em culturas administrativas legalistas. Eles concedem ao cidadão tutela jurisdicional individual e são ao mesmo tempo uma importante instância de controle (se não a mais importante) em relação ao Executivo. Tal posição central não se conquista repentinamente ("de ontem para hoje"). Muito pelo contrário. Ela tem que ser construída aos poucos pela percepção cuidadosa das competências delegadas. E, constantemente, ela se vê perante novos desafios. Novas possibilidades de ação da Administração Pública também alteram as atribuições dos tribunais administrativos. Identificar tais mudanças não é uma tarefa fácil para os tribunais. Isso requer manter uma certa distância de observação, o que o dia a dia dos tribunais não pode oferecer. Aqui, as ciências jurídicas administrativas têm uma função complementar importante. Retomarei esse tema no final da palestra.

As próximas apresentações tratarão de quatro temas: primeiramente, apresentarei um panorama da jurisdição administrativa alemã com base em suas principais características (II). Em seguida, falarei sobre a constitucionalização do direito processual dos tribunais administrativos (III). Na primeira parte, serão comentadas algumas questões clássicas, especialmente a questão do controle jurisdicional do poder discricionário da Administração Pública (IV). A quarta parte se ocupará com os novos desafios, incluindo os chamados conflitos baseados em informação $(\mathrm{V})$.

\section{II - AS PRINCIPAIS CARACTERÍSTICAS DA JURISDIÇÃO ADMINISTRATIVA ALEMÃ (PANORAMA)}

Esta primeira e breve parte traz à tona alguns pontos ${ }^{2}$ que são importantes para o entendimento da palestra ${ }^{3}$ :

(1) A Alemanha, como a maioria dos Estados europeus continentais, segue um modelo dualista que distingue entre os tribunais ordinários

2 Uma apresentação precisa em língua portuguesa se encontra na extensa obra de direito comparado de Sérvulo Correia, Direito do contencioso administrativo I, 2005, 77-121.

3 Em respeito à visão brasileira (também direito comparado), Perlingeiro, Aspekte der Verwaltungsgerichtsbarkeit in Brasilien, em: Jahrbuch des Öffentlichen Rechts, v. 62 (2014), 713 ss. 
para o direito civil e o direito penal e os tribunais competentes para contenciosos administrativos.

(2) Os tribunais administrativos são do ponto de vista organizacional e pessoal rigorosamente separados do Executivo. Não há formas intermediárias como aquelas apresentadas em alguns dos "tribunals" ingleses. A jurisdição administrativa é, ao lado dos tribunais ordinários, o segundo maior "pilar de apoio do Terceiro Poder".

(3) Os tribunais administrativos somente exercem atribuições da jurisprudência. Diferente, p. ex., do Conseil d'État francês, eles não têm a função de aconselhar o Governo.

(4) Existem três segmentos da jurisdição administrativa: tribunais sociais, tribunais financeiros e os tribunais administrativos gerais (em cuja apresentação eu focarei a seguir).

(5) No plano organizacional, a jurisdição administrativa é constituída por três instâncias. Basicamente, todos os processos se iniciam nos tribunais administrativos da primeira instância e podem então chegar aos tribunais administrativos superiores por meio do recurso da apelação e ao Supremo Tribunal Federal por meio da revisão.

(6) Os tribunais da primeira e segunda instância são tribunais dos "Estados"; somente a instância superior é um tribunal superior de justiça. As causas contra autoridades federais devem ser resolvidas na primeira e segunda instância perante os tribunais dos Estados; já as causas contra autoridades estaduais são decididas na instância de revisão pelo Supremo Tribunal Federal alemão. Essa mistura se explica pelo fato de que, no sistema federal alemão (diferente do Brasil e dos Estados Unidos), a maioria das leis federais também é executada por autoridades estaduais. ${ }^{4}$

(7) O direito processual dos tribunais administrativos está contido em uma codificação própria, no "Código do Procedimento Administrativo" (1960). O Código é rigorosamente separado do direito processual, o qual a Administração Pública tem que observar ao decretar as suas decisões, estando este codificado na "Lei do Procedimento Administrativo" (1976). É verdade que ambos os processos têm do ponto de vista histórico legal as mesmas raízes. Hoje, no entanto, eles devem ser separados: o direito processual da Administração Pública é multifuncional. Em contraste a isso, o direito processual

4 O cumprimento de leis federais por órgãos da União é a exceção e deve ser expressamente permitido na Constituição. 
dos tribunais administrativos tem apenas uma função central, a saber, possibilitar ao demandante uma tutela jurisdicional efetiva. Eu sei que isso em parte é visto de outra forma no Brasil.

\section{III - EXPERIÊNCIAS COM A CONSTITUCIONALIZAÇ̃̃O DO DIREITO PROCESSUAL ADMINISTRATIVO: O PAPEL DAS GARANTIAS DE TUTELA JURISDICIONAL, ESPECIFICAMENTE, DO ARTIGO 19, ALÍNEA 4, DA LEI FUNDAMENTAL DE 1949}

Passaremos agora à segunda parte da palestra. Essa parte se ocupará em especial com a constitucionalização do processo administrativo para a qual a fórmula fixada "efetividade da tutela jurisdicional" desempenha um papel central. O desenvolvimento da jurisdição administrativa é em todos os países um ponto de cristalização da evolução constitucional, pois trata-se da relação elementar man versus state. Na Alemanha, as discussões acerca dessa questão fundamental remontam à Idade Média. No século XIX, a introdução de uma jurisdição independente em ações administrativas foi uma exigência da burguesia liberal a qual já tinha sido atendida antes da Primeira Guerra Mundial na maioria dos Estados do império ${ }^{5}$. A Constituição de Weimar de 1919 pôde se reportar a esses resultados. Após os acontecimentos desastrosos sob o regime do Nacional Socialismo (1933-1945), a esperança da nova constituição, da Lei Fundamental (GG) de 1949, passou a repousar sobre um catálogo de direitos fundamentais os quais não são normas de programa, mas sim normas legais obrigatórias para o Legislativo, o Executivo e o Judiciário (art. 1ํㅗ § $3^{\circ}$, da GG); mais tarde, foi implementada uma poderosa jurisdição constitucional (art. $3^{\text {o }}$ da GG) e criada uma garantia abrangente de tutela jurisdicional contra atos do Poder Público (art. 19, § 4은, da GG).

\section{III.1 “O DIREITO ADMINISTRATIVO COMO DIREITO CONSTITUCIONAL CONCRETIZADO”: UMA FÓRMULA RECENTE PARA A CONSTITUCIONALIZAÇÃO DO DIREITO ADMINISTRATIVO}

A garantia de tutela jurisdicional tornou-se, em pouco tempo, a âncora mais importante dos tribunais administrativos e de seu direito processual. A evolução jurídica se une à fórmula "direito administrativo é direito constitucional concretizado". Ela provém de Fritz Werner, de um dos primeiros presidentes do Supremo Tribunal Federal alemão. Formulada em 1955, ela se tornou logo um paradigma marcante do direito administrativo alemão do período pós-guerra ${ }^{6}$.

5 Sobre o desenvolvimento Stolleis, Geschichte des Öffentlichen Rechts v. II, 1992, 240 ss.; Hufen, Verwaltungsprozessrecht, $7^{a}$ edição 2008, § 2; Sérvulo Correia, Direito (FN 3), 77-91.

6 Cf. Schmidt-Aßmann, Das Allgemeine Verwaltungsrecht als Ordnungsidee, 2. edição, 2004, capítulo 1, nota 17 ss. Na tradução em língua espanhola da $1^{a}$ edição (Marcial Pons, Madrid 2003), encontram-se as considerações correspondentes nas páginas 15 ss. 
Por conseguinte, todas as áreas do direito administrativo (especial) (direito do solo e das construções, direito das profissões industriais e comerciais, direito de polícia, direito atinente aos funcionários públicos) foram examinadas quanto à sua conformidade com a nova constituição, especificamente, com os direitos fundamentais. Todas as instituições do direito administrativo (geral) (ato administrativo, decreto, instrução) tinham que se justificar se elas correspondiam à imagem humana da Lei Fundamental, ou se eram uma expressão ultrapassada de "tradições estatais autoritárias" (p. ex., como a "relação de poder especial") que não podiam ser mais aceitas. O paradigma do direito constitucional concretizado deu vazão a uma enorme energia inovadora nas ciências jurídicas administrativas. Os tribunais administrativos, por sua vez, também seguiram esta ideia ${ }^{7}$. O direito administrativo alemão antecipou com esse paradigma uma evolução a qual é denominada reiteradas vezes como "constitucionalização" e que abrange hoje muitas outras áreas jurídicas, como o direito civil e outros Estados.

No entanto, em todos os aspectos, essa constitucionalização não é um avanço descomplicado. A indefinição dos critérios e a incerteza dos métodos são sobretudo criticados na concretização dos direitos fundamentais e humanos. Além disso, teme-se que o legislador parlamentar perca a sua influência quando os resultados são deduzidos diretamente da constituição e quando estes reivindicam a posição de direito constitucional ${ }^{8}$. No Brasil, também encontramos tal crítica da constitucionalização que se iniciou com a nova Constituição de $1988^{9}$.

\section{III.2 EsPECIAL SOBRE O PRECEITO CONSTITUCIONAL DA EFETIVIDADE DA TUTELA JURISOICIONAL NO DIREITO PROCESSUAL E NA PRÁtICA DOS TRIBUNAIS ADMINISTRATIVOS}

Quanto à jurisdição administrativa e ao direito processual administrativo, a constitucionalização dá pouca margem para crítica. A maioria dos resultados é hoje em geral aceita. Há duas razões decisivas para isso:

- De um lado, a constitucionalização pode se amparar em uma definição bem concreta da constituição. A saber (art. 19, alínea 4, da GG): "Toda a pessoa, cujos direitos forem violados pelo Poder Público, poderá recorrer à via judicial". Essa determinação representa um direito diretamente aplicável. Ela é claramente formulada e cita

7 Famosa é a decisão do Supremo Tribunal Federal alemão de 24. 6. 1954 (coletânea de jurisprudência BVerwGE 1, 159, 161: "O indivíduo está sujeito ao poder público, não como súdito, mas sim como cidadão"): Direito legal a assistência social.

8 Möllers, em: Hoffmann-Riem/Schmidt-Aßmann/Voßkuhle (Org.), Grundlagen des Verwaltungsrechts, 2. 2012 Vol. I, § 3, número de margem $13 \mathrm{f}$.

9 Krell, Die normative Ausgestaltung des brasilianischen Umweltrechts und die Hauptprobleme seiner methodisch abgesicherten Anwendung, em: Jahrbuch des öffentlichen Rechts, v. 62 (2014), 693 (706 ss.). 
os pontos mais importantes: tutela jurisdicional individual como proteção judiciária que deve ser abrangente e atuante ("efetivo").

- A segunda razão pela qual a constitucionalização da tutela do direito administrativo teve êxito reside na boa interação entre os tribunais administrativos e as ciências jurídicas administrativas. Um sempre deu estímulo ao outro. Da mesma forma, um controla o outro de modo que a constitucionalização se dá de forma consciente com base em um método. O Supremo Tribunal Federal alemão, cuja metade dos juízes vem da justiça e a outra, de universidades, desempenha neste processo um papel especialmente importante. $\mathrm{O}$ legislador confirmou este desenvolvimento: ele concebeu conscientemente o Código do Procedimento Administrativo de 1960 como uma lei para a concretização da garantia de tutela jurisdicional constitucional.

Os resultados mais importantes da constitucionalização da tutela jurisdicional constitucional são os seguintes:

- Os tribunais são competentes de acordo com uma cláusula geral. Atos de soberania que não podem ser controlados por causa de seu conteúdo político ("atos de soberania isentos de tribunais") não existem mais.

- $\quad$ Os tribunais não têm apenas o poder de anular atos administrativos; eles também podem obrigar a Administração Pública a agir de forma positiva.

- Devem existir também tipos de ações apropriadas para casos nos quais alguém queira se defender contra normas administrativas e contra atos reais da Administração Pública.

- $\quad$ Os tribunais têm a tarefa de controlar inteiramente as decisões administrativas. (Isso eu explicarei mais detalhadamente na terceira parte).

- $\quad$ Diferente do processo civil, no processo administrativo vale o princípio de instrução.

- $\quad$ A implementação das sentenças judiciais deve ser efetiva. Para isso, há regras de como essas sentenças podem ser cumpridas contra a Administração Pública. (Felizmente, essas regras praticamente não têm um papel importante, pois os tribunais administrativos gozam de grande respeito no meio público, e uma Administração Pública condenada raramente ousa não cumprir a sentença). 
- $\quad$ Por fim, deve haver instrumentos da tutela jurisdicional provisória: ao menos, a possibilidade de obter tutela jurisdicional urgente nos tribunais. De acordo com a opinião predominante, a constituição até ordena que ações de impugnação tenham um efeito suspensivo ("efeito suspensivo") o qual somente pode ser superado pela Administração Pública em circunstâncias especiais e por meio de ordem especial.

\section{IV - A EXATIDÃO DAS REVISÕES JUDICIAIS: “CONTROLE DE INTENSIDADE” COMO TEMA CLÁSSICO EATUAL}

A questão da intensidade do controle judicial é um dos grandes temas clássicos da tutela do direito administrativo. Antigamente, ela era tratada sob a figura dogmática do "poder discricionário da Administração Pública". Na maioria dos outros países, esse é também o termo usado. Na Alemanha, desenvolveu-se sob a influência da constitucionalização uma dogmática própria ${ }^{10}$. Ela usa outras definições e levou a um aumento da densidade de controle. Pode-se falar de uma "divisão de poderes influenciada pelo tribunal". Ela é também um símbolo da cultura administrativa legalista alemã. Outros países europeus e o Tribunal da União Europeia não vão tão longe. Na Alemanha, há visões críticas nas quais eu me incluo ${ }^{11}$. No entanto, o Supremo Tribunal Federal alemão recentemente voltou a confirmar este desenvolvimento ${ }^{12}$. As suas declarações principais são as seguintes:

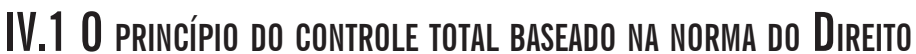

Em geral, é aceito o seguinte ponto de partida: o controle judicial se dá com base na norma do Direito correspondente, sobretudo com base na norma das leis parlamentares que devem controlar a Administração Pública. Onde não há normas legais, não pode haver um controle judicial. Os tribunais não são designados para exercer um "controle total".

Porém, as regulamentações legais para a Administração Pública na Alemanha são relativamente estanques. Isso, de um lado, se deve ao fato de que o princípio da legalidade da Administração Pública, ou seja, a pergunta quando a Administração Pública precisa de uma autorização legal para uma ação é definida de modo muito abrangente. Por outro lado, isso é uma consequência do preceito constitucional da determinação das leis. O legislador não precisa aspirar a uma medida máxima de determinação; o que se pede, no entanto,

10 Cf. a seguir Sérvulo Correia, Direito (FN 3), 104-109.

11 Schmidt-Aßmann, Das Allgemeine Verwaltungsrecht als Ordnungsidee (FN 7) capítulo 4, notas 73 ff.

12 BVerfGE 129, 1 (20 ss.). 
é uma determinação que seja suficiente. Cláusulas gerais vagas que delegam todo o resto ao Executivo não são permitidas. O legislador deve regulamentar as questões essenciais para os cidadãos.

É claro que isso não é possível sem usar termos legais indefinidos (qual termo legal é de fato definido?). A questão toda é que a indefinição de um termo legal não restringe o mandato de controle dos tribunais administrativos. Na utilização de termos legais indefinidos, os tribunais também têm a obrigação - de acordo com as três etapas da metodologia jurídica - de eles próprios definirem o termo, investigar os fatos existentes e realizar a subsunção. Vale o princípio do controle completo da aplicação do Direito ${ }^{13}$.

Se existia um "perigo" para a "segurança pública" e se por isso a polícia tinha o direito de proceder contra o causador do perigo, isso é decidido - quando se dá uma briga entre a polícia e a pessoa envolvida - pelos tribunais com base nesse princípio. O mesmo se aplica para a questão se o dono de um estabelecimento é "confiável", uma emissão é "aceitável" ou uma fábrica é "apta a receber incentivos". Se os tribunais não têm os conhecimentos necessários, estes devem então consultar peritos externos.

\section{IV.2 Exceç̃̃es CONFORME “Autorizaç̃̃ó NORMativa”}

O princípio do controle judicial completo apresenta exceções ${ }^{14}$. No entanto, tais exceções não derivam da circunstância de que a aplicação de um termo legal indefinido requer conhecimentos técnicos, econômicos ou ecológicos. Antes, sim, essas exceções deveriam estar previstas na própria lei. O legislador parlamentar tem, pois, o poder de autorizar a Administração Pública a tomar decisões vinculativas para constelações especiais e de reduzir respectivamente o controle dos tribunais.

- Isso ocorreu claramente naquelas situações em que as leis não obrigam a Administração Pública a agir, mas prescrevem que ela "pode" agir. Nesses casos da chamada "discricionariedade das consequências jurídicas", o controle dos tribunais é limitado.

- $\quad$ O controle também é limitado ali onde a Administração Pública é incumbida a contrapor de forma abrangente os interesses públicos e os interesses privados ("discricionariedade de planificação") na elaboração de planos, principalmente em obras de urbanização.

13 Nesta linha Schoch, em: Hoffmann-Riem/Schmidt-Aßmann/Voßkuhle(Org.), Grundlagen des Verwaltungsrechts, 2. edição, 2012, v. I, § 50, número de margem 252 ss.

14 Schmidt-Aßmann, em: Maunz/Dürig, Grundgesetz, Kommentar, art. 19, alínea 4, número de margem 188 ff. 
- $\quad$ Ademais, deve ser possível localizar as correspondentes autorizações por meio de interpretação das determinações legais correspondentes. Exemplos atuais podem ser encontrados ali onde a Administração Pública regula amplamente o mercado para serviços de telecomunicação ou para energia elétrica: a chamada "discricionariedade de regulação".

\section{IV.3 CRItÉrIos para um CONTROLE JUdicial ReduZIDO}

Diante do exposto, não se trata de excluir por completo o controle judicial, mas sim de reduzi-lo. Com base em que critérios os tribunais devem exercer esse controle reduzido? Há vários modelos que apresentam similaridades.

- Em todo o caso, deve-se verificar minuciosamente se a Administração Pública observou o respectivo Código do Procedimento Administrativo. O Código do Procedimento Administrativo tem aqui uma função compensatória para o controle substancial admissível com restrições.

- $\quad$ Além disso, a Administração Pública deve ter apurado os fatos completa e corretamente.

- $\quad$ Em terceiro lugar, a Administração Pública deve ter se orientado no propósito da respectiva autorização.

- $\quad$ Por último, ela não deve ter excedido os limites legais da autorização. Entre esses limites figura também o princípio da proporcionalidade: as medidas tomadas pela Administração Pública devem ser apropriadas e necessárias e não devem gerar desvantagens que sejam visivelmente desproporcionais em relação ao resultado almejado.

Se a decisão da Administração Pública se mantiver dentro desses limites, esta deve ser aceita pelos tribunais. Os tribunais se limitam aqui a reconstruir mentalmente as considerações da Administração Pública. Eles não substituem a subsunção da Administração Pública (o que não ocorre no princípio do controle completo) pela sua própria subsunção. Apesar disso, o controle judicial, nesse caso no qual ele é excepcionalmente reduzido, ainda é bastante intenso. Ele vai consideravelmente além de um controle discricionário segundo o antigo modelo de "détournement de pouvoir" ou de um mero "controle de evidência". De fato, observa-se uma intensificação lenta dos controles judiciais em outras ordens jurídicas europeias. No entanto, a intensidade do controle alemão (ainda) é o "número um". Apesar disso, com base em nossas experiências, a situação não chegou ao ponto de deixar a Administração Pública "paralisada". O controle judicial, na verdade, fortaleceu a legitimidade da Administração Pública. 


\section{V - O DESAFIO DOS “CONFLITOS BASEADOS EM INFORMAÇÃO”}

Na última parte de minha palestra, quero abordar o tema como os tribunais administrativos são desafiados por um tipo especial de litígio entre a Administração Pública e os cidadãos o qual eu chamo de "conflito baseado em informação".

\section{V.1 0 QUE SÃO CONFLITOS BASEADOS EM INFORMAÇÃO?}

Em conflitos dessa natureza, não está em jogo (ou pelo menos não em primeira linha) a decisão sobre o mérito da causa da Administração Pública, mas sim como a Administração Pública lida com informações. Portanto, a questão não é se um alvará de construção deve ser emitido, uma subvenção concedida ou uma proibição policial suspendida. As questões que de fato importam é se, por exemplo, a Administração Pública pode apurar determinadas informações, se ela pode encaminhar informações a terceiros ou se ela deve permitir o acesso às suas informações. A proteção de dados pessoais, a proteção de segredos empresariais e de Estado, freedom of information, naming and shaming são tópicos que caracterizam esse tipo de conflito.

Do ponto de vista sistemático, conflitos baseados em informação são objeto de um "direito administrativo da informação", cuja crescente relevância para todo o direito administrativo constitucionalizado foi corretamente definida há pouco tempo ${ }^{15}$. Trata-se de uma reação ao especial potencial de controle e ao especial potencial de risco que informações têm. Assim que as informações são levantadas pela Administração Pública e, sobretudo, quando estas são encaminhadas a terceiros pela Administração Pública, é praticamente impossível recuperar essas informações. Os conflitos baseados em informação são, além disso, frequentemente conflitos "multipolares", nos quais estão perante a Administração Pública duas pessoas físicas que reivindicam posições jurídicas contrárias.

Em respeito a isso tudo, comentaremos, a seguir, somente um pequeno recorte. A pergunta a ser levantada é se o direito processual administrativo e os seus instrumentos são adequados para assegurar uma tutela jurisdicional efetiva em conflitos baseados em informação.

\section{V.2 0 PROBLEMA DE UMA TUTELA JURISOICIONAL IMEDIATA}

A primeira pergunta é: a tutela jurisdicional pode ser obtida a tempo? Isso parece ser duvidoso em duas constelações:

15 Agora resumidamente Ino Augsberg, Informationsverwaltungsrecht, 2014; assim como Vesting, em: Hoffmann-Riem/Schmidt-Aßmann/Voßkuhle (Org.), Grundlagen des Verwaltungsrechts, v. II, § 20; antigamente já Schmidt-Aßmann, Das Allgemeine Verwaltungsrecht als Ordnungsidee (FN 7), capítulo 6, notas 3 ss. com outras exposições. 


\section{a) "A Administração Pública não deve simplesmente partir para o ato"}

Chamarei o primeiro destes grupos de "A Administração Pública parte simplesmente para o ato". Essa formulação remete a Otto Mayer, chamado frequentemente de o "pai" do direito administrativo alemão. Quando Mayer elaborou o seu direito administrativo de Estado de Direito ${ }^{16}$, ele mostrou o quanto é importante que a Administração Pública, antes de intervir em direitos dos cidadãos, decrete primeiramente uma decisão que tenha uma forma jurídica fixa e que deva ser comunicada à pessoa envolvida (destinatário). O resultado desta construção é o "ato administrativo" que somente pode ser imposto compulsoriamente contra a pessoa em questão em uma segunda etapa.

O ato administrativo ainda hoje é parte central da prática administrativa. A maneira como a tutela jurisdicional efetiva pode ser obtida contra ele está detalhadamente regulada no direito administrativo: por meio de recurso e de ação de impugnação, os quais, via de regra, têm um efeito suspensivo, impedindo dessa forma a execução compulsória ${ }^{17}$. Deve-se exigir que a Administração Pública basicamente também ali onde ela não quer ordenar ou proibir nada à pessoa em questão, mas sim se valer de seus direitos por meio de coleta de informações, emita antes uma decisão formal, isto é, um ato administrativo para que a pessoa em questão tenha a chance de se posicionar contra ele. O mesmo se aplica a casos em que a Administração Pública quer repassar dados pessoais ou empresariais ou quer, por exemplo, publicar "informações de consumidores" na internet.

Nos casos em que essa via não pode ser eleita, ou seja, quando uma ação de impugnação não é admissível, é necessário que o direito processual preveja outros tipos de ações. O Direito alemão dispõe de ação de cessação e de ação declaratória. Ambas as ações também são admissíveis como ações cautelares. Porém, diferente da ação de impugnação, elas não têm efeito suspensivo. O demandante precisa solicitar ao tribunal uma medida provisória. Os tribunais têm a obrigação de conceder generosamente essa forma da tutela jurisdicional provisória. Os danos que podem ocorrer devido à atividade de informação da Administração Pública são grandes, pois, uma vez que informações se tornaram públicas, estas normalmente não podem ser mais removidas.

16 Mayer, Deutsches Verwaltungsrecht, 2 v., 1. edição, 1895. Sobre Mayer em detalhe Stolleis, Geschichte des Öffentlichen Rechts, v. II, 403 ss.

17 Muitas vezes, a Administração Pública tem até a obrigação de juntar ao ato administrativo uma instrução de como se pode obter tutela jurisdicional contra ele, como, por exemplo, para atos administrativos de autoridades federais no $\S 37$, alínea 6, Lei do Procedimento Administrativo. 


\section{b) Levantamentos secretos de informação: "reserva de jurisdição"}

Mais difícil ainda é uma tutela jurisdicional efetiva perante informações as quais a Administração Pública apura secretamente, utilizando, para isso, meios eletrônicos. Mesmo em um Estado de Direito, não há como renunciar totalmente a esse tipo de ação estatal secreta, por exemplo, como no combate a crimes graves. Especialmente, em virtude do combate ao terrorismo internacional, o legislador parlamentar proveu a Administração Pública de competências de, em casos extremos, decretar o monitoramento eletrônico de residências, o que representa uma grave infração contra o direito fundamental da não violação da esfera privada ${ }^{18}$. Estabeleceu-se que a Administração Pública, antes de cometer tais infrações, precisa da autorização do juiz ${ }^{19}$. Sem uma decisão judicial, a Administração Pública somente pode agir por "perigo da demora".

Esta chamada "reserva de jurisdição" representa uma forma de tutela jurisdicional preventiva. A prática mostra, porém, que os juízes competentes não examinam suficientemente o caso e que estes talvez até se identifiquem muito rapidamente com os interesses da Administração Pública. Tais competências especiais são sempre um problema. As práticas com tribunais secretos na contraespionagem dos EUA reiteram isso com mais veemência ainda. Por isso, hoje em dia, reconhece-se que a reserva de jurisdição é apenas uma primeira etapa de uma tutela jurisdicional efetiva. Assim que não houver mais uma razão para manter o levantamento de informação sigiloso, a Administração Pública tem o dever de informar a pessoa em questão. Ela deve lhe dar a possibilidade de interpor ação perante os tribunais administrativos de que o levantamento sigiloso da informação foi ilegal. Essa ação pode ser seguida de ações de indenização e de extinção ou de retificação das informações apuradas.

\section{V.3 O TRATAMENTO DE INFORMAÇÕES SIGILOSAS NO PROCESSO ADMINIITRATIVO: PROCESSO A PORTAS FECHADAS}

Gostaria de discutir brevemente um segundo problema insistente em relação aos conflitos baseados em informação: como o tribunal deve proceder quando a Administração Pública em um processo apresenta como fundamentação que determinadas informações representam um segredo de Estado? Antigamente, bastava que a autoridade provasse ao tribunal as suas motivações para essa afirmação; ela não precisava apresentar os respectivos autos ao tribunal. O Supremo Tribunal Federal alemão decidiu, no entanto, que isso negava aos demandantes uma tutela jurisdicional efetiva. Por meio de uma alteração no

18 A Lei Fundamental foi complementada com uma emenda constitucional, art. 13, alínea 3-6, com a maioria requerida.

19 Neste caso, a competência não recai sobre os tribunais administrativos, mas sim sobre os tribunais ordinários, que também são competentes, por exemplo, para as decisões sobre a decretação de prisão (art. 104, GG). 
direito processual, teve que ser introduzido um processo especial a portas fechadas: nesse processo, a Administração Pública tem que apresentar todos os seus autos a um senado especial do tribunal que deve manter sigilo absoluto. Este decide se realmente há um sigilo a ser protegido sem que outras partes consultem os autos.

- Se a proteção de sigilo for negada, a Administração Pública terá que comunicar ao tribunal do processo as informações, e todas as partes poderão consultar os autos.

- Se a proteção de sigilo for reconhecida como de direito, o tribunal do processo não terá conhecimento das informações em questão. O tribunal do processo deve então, de acordo com as regras gerais, decidir sobre a distribuição do ônus da prova no processo administrativo.

Hoje em dia é discutível se essa regulamentação garante uma tutela jurisdicional efetiva ou se infringe a Constituição. Essa disputa é travada no âmbito da jurisdição e das ciências jurídicas administrativas ${ }^{20}$. Soluções adequadas somente serão encontradas quando ambos os lados contribuírem para isso. Isso vale para o tema dos conflitos baseados em informação; sim, isso se aplica a todos os desafios modernos com os quais os tribunais administrativos se veem confrontados.

\section{VI - CONCLUSÃO: A RELAÇÃO COMPLEMENTAR ENTRE A JURISDIÇÃO ADMINISTRATIVA E AS CIÊNCIAS JURÍDICAS ADMINISTRATIVAS: DOGMÁTICA DO DIREITO ADMINISTRATIVO}

Volto a retomar agora no fim o tema que comentei introdutoriamente o qual tem especial importância para mim: a relação entre a jurisdição administrativa e as ciências jurídicas administrativas. A relação deve ser de boa cooperação a qual foi elaborada complementarmente ${ }^{21}$. A ciência não deve se movimentar sozinha em divagações teóricas abstratas. Contudo, ela também não deve apenas apresentar e comentar o Judiciário por escrito. Antes de mais nada, ela deve de fato analisá-lo e classificá-lo em linhas de evolução, assim como transmitir a orientação. Incluídos estão também os conhecimentos da história do direito e do direito comparado. Da mesma forma, fazem parte a intuição, a inovação e a força para a formação de um sistema.

20 Exposições sobre o assunto em Schoch, em: Hoffmann-Riem/Schmidt-Aßmann/Voßkuhle (Org.), Grundlagen des Verwaltungsrechts, v. III, § 50, número de margem 245 ss.

21 Nesse contexto, do ponto de vista prático, parece ser importante uma interação de funcionários: juízes são muitas vezes docentes contratados ou professores honorários em Faculdades de Direito e têm dessa forma participação na doutrina acadêmica. Não raras vezes, professores de Faculdades de Direito são juízes em tribunais superiores; o exercício da advocacia não lhes é permitido. 
O fórum de discussão ideal entre ambos, entre as ciências jurídicas administrativas e a jurisdição administrativa, é por isso uma boa dogmática do direito administrativo ${ }^{22}$. Uma boa dogmática une estabilidade e flexibilidade. Ela é uma tarefa comunitária da qual a legislação e a prática administrativa participam. Mas os agentes principais são e permanecem sendo as ciências jurídicas administrativas e a jurisdição administrativa.

22 Schmidt-Aßmann, Verwaltungsrechtliche Dogmatik, 2013. 
Supremo Tribunal Federal

08.05.2003 Tribunal Pleno

Ação Direta de Inconstitucionalidade n $2.656-9$ São Paulo

Relator: Min. Maurício Corrêa

Requerente: Governador do Estado de Goiás

Advogados: PGE/G0 - Bruno Bizerra de Oliveira e outro

Requerido: Governador do Estado de São Paulo

Requerida: Assembléia Legislativa do Estado de São Paulo

EMENTA

AÇÃO DIRETA DE INCONSTITUCIONALIDADE-LEI PAULISTA - PROIBIÇÃO DE IMPORTAÇÃO, EXTRAÇÃO, BENEFICIAMENTO, COMERCIALIZAÇÃO, FABRICAÇÃO E INSTALAÇÃO DE PRODUTOS CONTENDO QUALQUER TIPO DE AMIANTO - GOVERNADOR DO ESTADO DE GOIÁS - LEGITIMIDADE ATIVA - INVASÃO DE COMPETÊNCIA DA UNIÃO

1. Lei editada pelo Governo do Estado de São Paulo. Ação direta de inconstitucionalidade proposta pelo Governador do Estado de Goiás. Amianto crisotila. Restrições à sua comercialização imposta pela legislação paulista, com evidentes reflexos na economia de Goiás, Estado onde está localizada a maior reserva natural do minério. Legitimidade ativa do Governador de Goiás para iniciar o processo de controle concentrado de constitucionalidade e pertinência temática.

2. Comercialização e extração de amianto. Vedação prevista na legislação do Estado de São Paulo. Comércio exterior, minas e recursos minerais. Legislação. Matéria de competência da União (CF, art. 22, VIII e XIII). Invasão de competência legislativa pelo Estado-membro. Inconstitucionalidade.

3. Produção e consumo de produtos que utilizam amianto crisotila. Competência concorrente dos entes federados. Existência de norma federal em vigor a regulamentar o tema (Lei no 9.055/1995). Consequência. Vício formal da lei paulista, por ser apenas de natureza 